\title{
Using Undergraduate Mentors to Scale the Teaching of Engineering Writing
}

\section{Mr. Michael Alley, Pennsylvania State University, University Park}

Michael Alley is an associate professor of engineering communication at Pennsylvania State University. He is the author of The Craft of Scientific Writing (Springer, 2018) and The Craft of Scientific Presentations (Springer, 2013). He also is the founder for the popular engineering communication websites: the Assertion-Evidence Approach (www.assertion-evidence.com) and the Writing Guidelines for Engineering and Science (www.craftofscientificwriting.com). 


\section{Using Undergraduate Mentors to Scale the Teaching of Engineering Writing}

Many engineering colleges have standalone courses to teach writing to engineering undergraduates. Often, these courses reside in departments of English. For example, such a course with multiple instructors teaching several sections each semester can be found in the English Department at Rose-Hulman [1]. In other colleges, the standalone courses reside in the college of engineering itself with a prominent example being at the University of WisconsinMadison [2]. Still, in other colleges, the courses reside in the engineering departments. An example here would be the standalone technical communication courses in the Departments of Chemical Engineering, Mechanical Engineering, and Civil and Environmental Engineering at the University of Texas at Austin [3]. Finally, rather than using a standalone course to teach writing, a number of engineering departments try to interweave the teaching of writing into a sequence of engineering courses. Such a course sequence occurs with two upper-level laboratory courses in the Mechanical Engineering Department of Virginia Tech [4].

However, with recent increases in engineering undergraduate enrollments [5], many such courses are stretched. Faculty are asked to teach greater loads, often without additional resources. One such example is Pennsylvania State University, a large land-grant institution, in which the English Department has historically taught engineering undergraduates in a required technical writing course. Originally listed at the sophomore level, this course has fallen behind in teaching engineering students at that level. In fact, many Penn State engineering students on the University Park campus claim that they cannot find a seat in the course until their senior year. For that reason, many engineering students at Penn State take technical writing over the summer at other institutions, often community colleges. In addition, engineering departments in the College have had to allow students who have not taken the technical writing course to enroll in upper-level laboratory and design courses that are writing intensive and have the technical writing course as a prerequisite. Even more of a problem, many Penn State engineering students work in internships and co-op experiences without having taken the technical writing course, even though the companies expect those students to write. Worse yet, in those internships, our students are evaluated alongside engineering interns who have had the experience of a technical writing course.

To address this situation, the Mechanical Engineering Department at Penn State has piloted an engineering writing course that connects to its required junior-level design course, which is writing intensive. What distinguishes this engineering writing course from traditional technical writing courses is that the instructor is progressively scaling up the course to accommodate larger numbers of students than what an instructor could handle in traditional technical writing courses. In the fall 2017 semester, the instructor accommodated 50 students in two sections, and in the spring 2018 semester, the instructor allowed that number to rise 75 students across two sections. For the fall 2018 semester, the plan is to accommodate 100 students across two sections. To assist the instructor in the mentoring and grading, the course uses a team of undergraduate mentors. These undergraduates have excelled in the engineering writing course. 
While technical writing courses such as at the University of Texas at Austin [3] and engineering courses such as in the Mechanical Engineering Department at Virginia Tech [4] use graduate students to assist in the teaching, mentoring, and grading of writing, no other course to our knowledge has used undergraduate mentors for this purpose and at this scale. At present, we are using 10 mentors to teach writing to about 75 mechanical engineers in an engineering writing course. In addition, we are using those 10 and an additional 5 for the writing and speaking component of a required design course, which has more than 200 mechanical engineers.

Using undergraduates as opposed to graduate students offers a number of advantages. The first is a much more sustainable budget model for the department. At Penn State, a graduate student teaching assistantship costs $\$ 21,500$ per semester: $\$ 10,400$ salary plus 15.4 percent fringe benefits plus $\$ 8500$ tuition. For this assistantship, the graduate student is to work 300 hours. In contrast, if undergraduate mentors (who are paid $\$ 15$ per hour) were used for those 300 hours, the cost would be only $\$ 4500$. Put another way, per hour, a graduate student is more than four times as expensive as an undergraduate. A second advantage of using undergraduate mentors is the familiarity that the undergraduate mentors have with the technical content and structure of the junior-level design course (as compared with a graduate student who came from another institution). As with a graduate student, undergraduate mentors not only earn money to help offset the increasing costs of tuition [6], but also gain valuable mentoring and editing experience to place on their résumés.

This proof-of-concept paper addresses the following research question: Is our approach of using undergraduate mentors to scale a technical writing course feasible? To address this primary research question, the paper first considers the following secondary questions:

1. Will students enroll for our course, especially in the second semester?

2. Will students resist the approach of our course?

3. Will students challenge having undergraduate mentors provide writing advice and grading?

4. Will the undergraduate mentors, who are taking full course loads, be able to provide sufficient hours to help the writing instructor handle the mentoring and grading loads?

5. Will the grading remain consistent across the different mentors?

6. In general, how do the portfolios of writing assignments created in the pilot course compare with the published portfolios from technical writing courses?

To answer these questions, this proof-of-concept paper first provides background on the goals and structure of the pilot course. Then the paper describes the selection, training, and management of the mentors for the course. Given next is a description of the course's critiquing sessions, which are modeled after the Iowa Writers Workshop. Following that are preliminary results of the research questions listed above. Those answers arise from general observations by the instructor across one and a half semesters. Then the paper presents a broader impact of the course: two transferable modules (one on correspondence and one on report writing). Finally, the paper concludes with thoughts about a formal assessment of this new approach. If found to be successful, this new approach would present an alternative paradigm for teaching writing in large engineering colleges. 


\section{Background: Although the course goals and structure are similar with traditional courses in technical writing, the connection with the design course deepens the content}

Like many traditional technical writing courses, our pilot course (Effective Engineering Writing) consists of goals specific to engineering writing. These goals include targeting the audience, learning strategies for types of documents commonly written by engineers, adopting a style that serves such documents, and developing a process that can meet professional deadlines. The course goals appear in Table 1.

Table 1. Goals of Pilot Course.

$\begin{array}{ll}\text { Category } & \text { Goal } \\ \text { Audience } & \text { To be able to communicate engineering messages to varied audiences } \\ \text { Genre } & \begin{array}{l}\text { To demonstrate the ability to structure emails, proposals, and reports so that they are logical, } \\ \text { achieve an appropriate depth, and emphasize important details } \\ \text { To learn strategies for writing other common types of technical documents: instructions, posters, } \\ \text { and web pages } \\ \text { To create a portfolio of your own engineering writing to share with recruiters } \\ \text { To be able to craft sentences that are both precise and clear and to be able to connect those } \\ \text { sentences into paragraphs that maintain energy }\end{array} \\ \text { Forme } & \begin{array}{l}\text { To be able to incorporate effective illustrations and equations into an engineering document } \\ \text { To be able to design documents such that they are professionally formatted and free of distracting } \\ \text { grammar, punctuation, and usage errors }\end{array} \\ \text { Process } & \text { To be able to plan, draft, revise, and finish documents in a timely manner }\end{array}$

In this pilot course, we have adopted the following educational model used for teaching engineering students to write consists of the following four steps:

1. Students receive instruction on the specific form and style of writing in engineering [7]

2. Students write a meaningful engineering document [8]

3. Students receive valuable feedback on that document that reinforces the instruction given in the first step

4. Students write a revision of the document that incorporates the provided feedback. In this model, the instruction occurs through reading [7] and through class lectures and discussion. In this model, the word meaningful refers to the students writing a document that they care about. Ideally, that document has an actual audience, purpose, and occasion. The valuable feedback in the third step refers to feedback that challenges the student not only on style and form, but also on feedback. In this model, learning occurs at all four stages.

Also, as in typical technical writing courses, the course incorporates formal classes to discuss principles of writing as an engineer, outside reading on those principles, a series of assignments to have students apply those principles. Again, as with many technical writing courses [1-3], most of the assignments in Effective Engineering Writing follow a sequence. In Effective Engineering Writing, the three connected assignments are as follows:

1. handout for a research presentation on a design topic (such as wind turbines),

2. proposal of a concept to prototype, and

3. final report on that design (with instructional appendix for using the design). 
Having a connected sequence streamlines the content gathering aspect of the writing process. Shown in Table 2 is an abbreviated sequence of class periods and assignments for the course.

Table 2. Abbreviated Sequence of Class Periods and Assignments for Pilot Course.

\begin{tabular}{rll} 
Week & Topics & Assignments and Online Quizzes \\
\hline 1 & Emails (Audience, Purpose, Occasion); Structure of Emails & Diagnostic Paragraph \\
2 & Language: Being Precise, Clear, and Connected; Controlling Tone & Grammar Quiz \\
3 & Workshop on job application email & Punctuation Quiz \\
4 & Researching a Subject: Gathering and references sources & Job Application Email \\
5 & Language: Sustaining energy and connecting ideas & Usage Quiz \\
6 & Workshop on research handout & Quiz on Referencing Sources \\
7 & Proposals: Approach, Structure, and Winning Strategies & Research Handout \\
8 & Organization (Titles and Sections); Language (Being Familiar) & \\
9 & Workshop on proposals & Proposal \\
10 & Organization of Formal Reports; Emphasis in Formal Reports & \\
11 & Process of Writing: Planning, Drafting, Revising, Finishing & \\
12 & Instructions; Professional Formats & \\
13 & Posters and Web Pages & Final Report \\
14 & Workshop on final report & \\
15 & Summary of Course &
\end{tabular}

One feature of Effective Engineering Writing, which does not occur in many technical writing courses, is that the three sequenced assignments are the same documents submitted in the junior design course. Two advantages and one disadvantage arise here. One advantage is that the content of the writing in Effective Engineering Writing is deeper and more technical than the content in documents of most technical writing courses. One reason is the students have two readers: (1) an engineering faculty member or graduate student who scores the precision and depth of the content, and (2) another reader (the writing instructor or undergraduate mentor) who scores the style and form of that content. As given in Appendix A, style addresses structure, language, and illustration, and form addresses grammar, punctuation, usage, and format. Note that because both the writing instructor and the undergraduate mentors understand the content of the design project, they are able to address the boundary between being precise and being clear. For even an experienced technical writing teacher, who might have twenty different research topics in a class, the ability to comment on precision is challenging.

Another advantage of our approach is the depth of the content. Assuming that a student in a typical technical writing course spends 3 hours outside of class for every hour in class on assignments and assuming that 2 of those hours are spent on the writing, the student would spend at most 15 hours researching the topic of the document sequence. However, because each student in Effective Engineering Writing has one entire design course (with 2 hours of large lecture and 3 hours of lab) dedicated to the semester-long design project, the student is able to dive more deeply into a topic. That depth surfaces in the equations and illustrations that students incorporate. For instance, for this semester's project, the student teams have to design a smallscale wind turbine, such as the one shown in Figure 1. This wind turbine is to provide enough power to run a humanitarian application such as an LED light in a family dwelling.

One calculation in each proposal is the projected efficiency of the designed wind turbine. To perform that efficiency calculation, the students first have to show their calculation of the torque supplied by the rotor, $T_{\text {rotor_s }}$, which is defined in equation 1 : 


$$
T_{\text {rotor } s}=\frac{1}{2} C_{m} \rho A R U^{2}
$$

where $C_{m}$ is the rotor-torque coefficient, $\rho$ is the air density, $A$ is the rotor's cross-sectional area, $R$ is the radius of the rotor, and $U$ is the air velocity. Likewise, one illustration that is part of the design process is the matrix for concept selection. Shown in Table 3 is an example of such a matrix. In the design proposal, several technical illustrations of this depth occur: a table showing the customer needs and accompanying metrics and specifications; a diagram of the functional decomposition; matrices similar in detail to the concept scoring matrix shown; and a Gantt chart. Few proposals written in typical technical writing course would have that breadth or depth of illustrations.

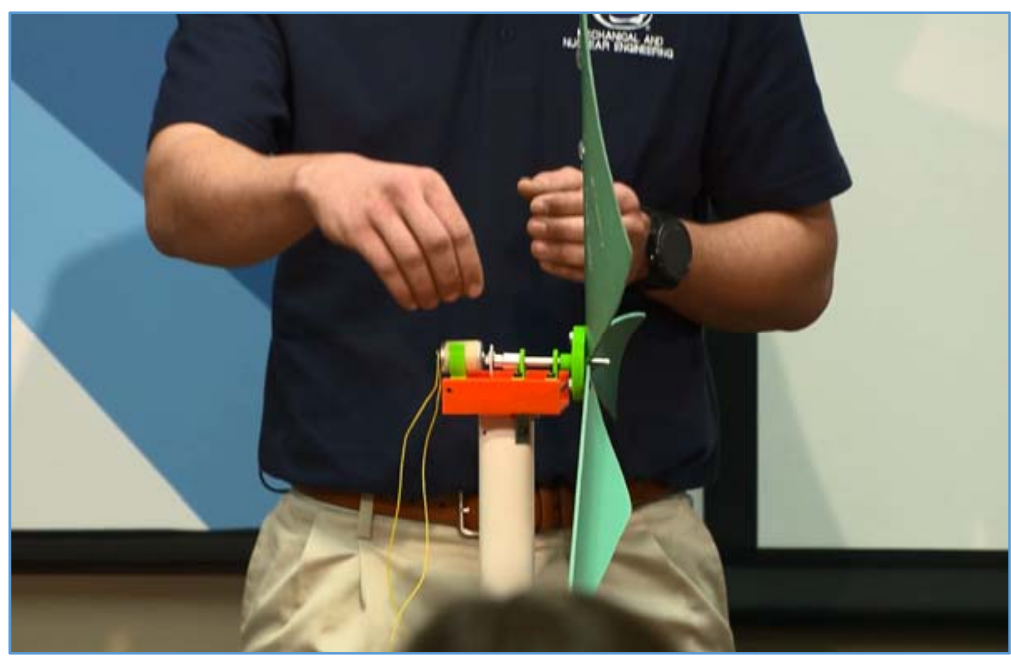

Figure 1. Small-scale wind turbine designed by a team of three students in a junior-level design course [9]. This image was a scene from the team's final presentation. In the pilot writing course, the corresponding writing assignment for this scene is the final report.

Table 3. Example of a concept scoring matrix that occurs in the design proposal [10].

\begin{tabular}{|c|c|c|c|c|c|c|c|c|c|c|}
\hline & & \multirow[b]{2}{*}{ Weight } & \multicolumn{2}{|c|}{ Print in Pieces } & \multicolumn{2}{|c|}{$\begin{array}{l}\text { Print Parts Involved with } \\
\text { Fallure }\end{array}$} & \multicolumn{2}{|c|}{ Part Moves } & \multicolumn{2}{|c|}{ Part Can be Ordered } \\
\hline & & & Rating & $\begin{array}{l}\text { Weighted } \\
\text { Score }\end{array}$ & Rating & $\begin{array}{l}\text { Weighted } \\
\text { Score }\end{array}$ & Rating & $\begin{array}{l}\text { Weighted } \\
\text { Score }\end{array}$ & Rating & $\begin{array}{l}\text { Weighted } \\
\text { Score }\end{array}$ \\
\hline \multirow{6}{*}{ 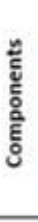 } & Dryer Cylinder & 0.067 & 5 & 0.33 & 5 & 0.33 & 5 & 0.33 & 4 & 0.27 \\
\hline & Non Drive End Bearing & 0.089 & 3 & 0.27 & 2 & 0.18 & 5 & 0.44 & 4 & 0.36 \\
\hline & Drive End Bearing & 0.078 & 5 & 0.39 & 5 & 0.39 & 5 & 0.39 & 4 & 0.31 \\
\hline & Siphon & 0.048 & 1 & 0.05 & 1 & 0.05 & 1 & 0.05 & 1 & 0.05 \\
\hline & Thermorims & 0.074 & 1 & 0.07 & 2 & 0.15 & 1 & 0.07 & 1 & 0.07 \\
\hline & Steam Inlet Pipe & 0.084 & 1 & 0.08 & 5 & 0.42 & 1 & 0.08 & 3 & 0.25 \\
\hline \multirow{4}{*}{ 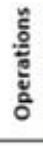 } & Hizhlizhts Misaliznment & 0.067 & 5 & 0.34 & 5 & 0.34 & 3 & 0.20 & 3 & 0.20 \\
\hline & Highlights Corrosion & 0.092 & 5 & 0.46 & 5 & 0.46 & 3 & 0.28 & 3 & 0.28 \\
\hline & Highlights Vibration & 0.092 & 5 & 0.46 & 5 & 0.46 & 4 & 0.37 & 3 & 0.28 \\
\hline & Full Working Subsystem & 0.032 & 5 & 0.16 & 3 & 0.10 & 4 & 0.13 & 1 & 0.03 \\
\hline \multirow{5}{*}{$\begin{array}{l}\bar{\Xi} \\
\text { ֻूँ }\end{array}$} & Manufacturability & 0.070 & 3 & 0.21 & 4 & 0.28 & 1 & 0.07 & 1 & 0.07 \\
\hline & Print Time & 0.089 & 3 & 0.27 & 4 & 0.36 & 3 & 0.27 & 1 & 0.09 \\
\hline & Scaling & 0.119 & 5 & 0.59 & 5 & 0.59 & 3 & 0.36 & 1 & 0.12 \\
\hline & & Total Score & \multicolumn{2}{|c|}{3.68} & \multicolumn{2}{|c|}{4.10} & \multicolumn{2}{|c|}{3.04} & \multicolumn{2}{|c|}{2.37} \\
\hline & & Rank & \multicolumn{2}{|c|}{2} & \multicolumn{2}{|c|}{1} & \multicolumn{2}{|c|}{3} & \multicolumn{2}{|c|}{4} \\
\hline
\end{tabular}


One distinct disadvantage of the course structure for Effective Engineering Writing is that students work in teams of two to four on the design project. For that reason, all three assignments in the major sequence are collaborative projects. Granted, the experience of collaborative writing is valuable since so much writing in engineering is collaborative. Still, we have a difficult time knowing whether the quality of a handout, proposal, or final report arises from a particular student in the writing course or from others on the team. For instance, if a team document earns an A, how do we know whether that A-level writing arose because of the planning, drafting, revising, and proofreading of each team member who is in the writing course? Likewise, does a lower grade arise because the writing student on the team is weak or did that student produce the best document in the time allotted with the talent she or he had on the team? Certainly, we can use surveys in both the writing course and design course to mine for this information, but the correlation of team performance with individual contribution on writing assignments remains a challenge.

\section{Background: To scale the number of students served, the course relies on undergraduate mentors to mentor and grade}

As mentioned, the course is able to scale the number of students served by relying on undergraduate mentors who have already taken the design course and have excelled in the writing portion. The number of mentors in the engineering writing course is quite large with all having dual roles as writing and speaking mentors in the junior-level design course. For instance, this semester, we have more than ten mentors to handle the writing in the engineering writing course, which has more than 75 students. In addition, those ten mentors are part of the fifteen mentors to handle the mentoring and grading of writing in the junior design course, which has more than 200 students. The main reason for the large number of mentors is to ensure that we have enough mentors during those parts of the semester in which the mentors have tests and project deadlines. A philosophical stance of this effort is that the courses taken by the writing mentors come before their mentoring duties. Finally, the selection of the mentors has maintained a 50-50 gender balance, even though only 15 percent of the mechanical engineering undergraduates are female. Becoming a mentor is highly valued, as evidenced by the prominence the mentors give the position on their resumes and Linked-In pages.

Training of the mentors has involved preparing the mentors for mentoring and grading duties in the days before they perform those duties. Although mentors do little formal teaching, mentors do give a sample research presentation, proposal presentation, and final presentation in the large design course. Before such presentations, the students practice a model team presentation (with speaker notes in the notes pages of the PowerPoint) beforehand. That practice includes a rehearsal with the writing instructor the evening before the classroom performance. Mentors generally receive no formal training before mentoring sessions on speaking and writing. However, mentors do receive access to the assignments and lecture slides, which they are familiar with from their own course experience. In addition, the mentors receive emails discussing particular questions and issues that have arisen in class this semester. For instance, if the class emphasized how to write the subject line of an email in more detail than previous semesters, the writing instructor made the mentors aware of that. 
Much of the training occurs before the grading of assignments. Generally, on the Friday afternoon that a major assignment comes in, we have a grading workshop in which we go over the grading rubric (see Appendix A for a common example). In addition, we walk through the grading of a strong example and not-so-strong example. In the grading, all of which occurs with file copies of Microsoft Word documents, we change the type color of the strong passages to blue, change the type color of errors and weaknesses to red, and insert suggestions in green type. Where appropriate, we write comments. All graders are encouraged to email the instructor with any questions about a passage, such as whether a particular word group is a run-on. In such situations, the grader simply writes an email with the subject line "Run-on?" with the text of the email then being only the group of words cut and pasted from the document. Then the instructor emails back with the answer. Such exchanges are efficient, which follows a grading principle of the course: to provide the most valuable feedback to the student in as efficient a time as possible.

Management of the undergraduate mentors continues to evolve. For their work, mentors earn $\$ 15$ per hour. Every two weeks, mentors submit their hours through an online management system. To sign up for tasks, mentors sign up on a Google sheet that the instructor manages. Tasks include grading daily quizzes, running critique workshops of three to six students, grading major assignments, and special assignments, such as creating a format template in Microsoft Word for the proposal.

\section{Background: Rather than having students bring drafts to class for on-the-spot critiquing, the course runs more formal critiquing based on the Iowa Writers Workshop}

One feature that distinguishes the course is the course's peer critiquing, which follows the Iowa Writers' Workshop for creative writing [11]. In this approach, the students submit their assignment excerpts at least two days before the workshop so that the peers and often a mentor have the chance to read, reflect, edit, and summarize their critiques. In addition, for most critique groups, either the instructor or one of the undergraduate mentors run the session and hold attendees accountable for their submissions and critiques. Because this approach allows for reflection after the reading, the strategy often achieves deeper critiquing comments than the common approach in which students just show up to class with a draft to share. Shown in Figure 2 is a scene of one such workshop.

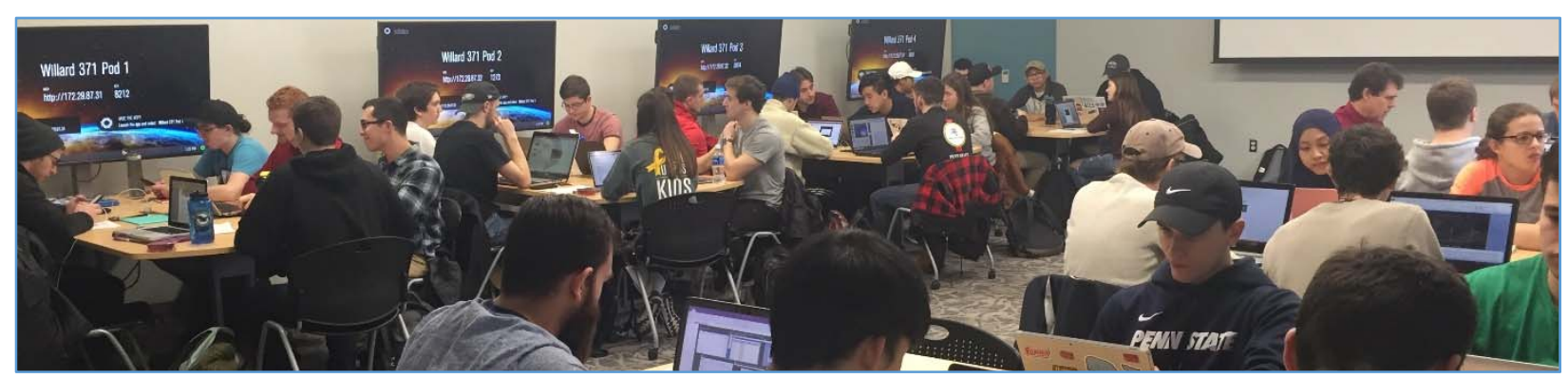

Figure 1. Scene from formal workshop on the research handout. Students received access to the drafts two nights before the workshop and posted comments through the course management system. At this workshop, about half of the critique tables had a mentor. 
Because each critique group consists of four to six students and often one mentor, this approach would be taxing for one instructor teaching 20 to 30 students. However, because our course has a stable of experienced mentors, we can have several simultaneous critique sessions for a class of 42 students. In addition, for the critiquing sessions, we use a special classroom (shown in Figure 2) that has conference-style tables. Each table, which seats six students and a mentor, has a large computer monitor on one end such that each manuscript can be projected to allow for targeted discussion of a passage.

\section{Preliminary Results: The approach of scaling technical writing by using undergraduate mentors shows much promise, but faces significant challenges}

For this proof-of-concept paper, the goal was not a rigorous assessment of the main research question, but a general decision on whether the concept warrants continuing with a formal assessment of the approach in coming semesters. Before answering the primary research question, we considered the secondary research questions. Provided in Table 4 are our answers to the secondary questions.

Table 4. Answers to Secondary Research Questions.

\section{Question}

Did students enroll for this course for first semester?

Did students enroll for course in second semester?

Did students resist the approach of the course?

Did students challenge having senior mentors as graders?

Were the mentors able to find time to do the work?

Was grading consistent across different mentors?

How do portfolios of the pilot course compare with published portfolios of technical writing courses?
Answer

Yes (50)

Yes (75). However, we need to find out why no honors students enrolled.

No: at least not in course surveys or complaints to undergraduate office

No: at least not in course surveys or through complaints to undergraduate office

Most times, yes. However, we often did not have enough mentors for the workshop and for the final report in the fall, we had almost no graders

The numerical averages were, but a formal assessment is needed to determine if the comments were.

Although the comparisons were not apples to apples, the pilot course portfolios were similar in style and form.

First, students did enroll in the pilot course, both in the first semester (at the 50 person limit) and in the second semester (near the 80 person limit). In a rigorous assessment, we need to analyze why no honors students enrolled in the course, even though those students have early registration for courses. Perhaps those students had already taken the university's technical writing course during their sophomore year. Still, we need to address that question. Another interesting question to monitor in the future is whether international students are more or less likely to enroll in the course. In the Department of Mechanical Engineering at Penn State, international students constitute 18 percent of the undergraduate population. Knowing whether international students are more or less likely to register for the course provides a glimpse into how well the course teaches such students. 
For the second grouping of questions, students in the course resisted neither the different approach of the course nor the use of undergraduate mentors for running the critique sessions or for grading the assignments. One comment that we heard in surveys was that taking this pilot writing course was a more efficient use of time because the content for the major assignments arose from the content already generated in another course. Also, no significant complaints arose either in surveys or in the Department's undergraduate office about the grading in the writing course, even though the GPA for the writing course was significantly lower than in the design course.

With regard to the third grouping of questions, except for the end of the fall semester, we had enough graders to handle the grading of the quizzes and major assignments. At this point, we do not have enough mentors to have a mentor in each critique group. Still, we change critique groups in each workshop so that students have a mentor-led critique table every other workshop. In retrospect

Over the past semester and a half, managing the team of mentors has been an ongoing learning experience. Some lessons learned were as follows:

1. A Google sheet is an effective way to do sign-ups - students looking for hours to work typically scan the sheet over the weekend

2. Dedicating one mentor to manage quizzes in each section is also efficient - although mentors like challenging tasks such as speaking to the large design class of 200 students, they sometimes wanted low-stress tasks such as grading quizzes over the weekend.

3. Having the instructor and students post their grades on a Google sheet as the grading occurs is an excellent way to keep everyone's averages about the same.

Finally, we informally compared the portfolio documents of our stronger students with a award winning journal (Illumin) of student articles that arise from the technical writing course at the University of Southern California [12]. In general, this online journal targets a wider audience and has a wider array of interesting subjects, such as a floating tunnel for vehicles proposed along the coastline of Norway. However, the best documents in pilot course fared well with the published articles in Illumin in terms of also being well organized, presenting details in a methodical fashion, and having clear and connected sentences. In addition, as with the articles in Illumin, the stronger documents from the pilot course referenced credible sources, were clean as far as grammar, punctuation, and usage, and followed a professional looking format. One advantage of the documents from the pilot course was that those documents had more depth. However, such a depth was to be expected since the students in the pilot writing course were working in a design team and had the dedicated time and technical perspective of the design course.

Given the generally positive response of the answers to the secondary questions, our answer for the primary research question is a qualified "yes." The approach of using undergraduate mentors to scale a technical writing course that aligns its assignments with a technical design course shows promise. In particular, the students are able to achieve technical depth on their writing assignments. They also receive technical assessments from the instructors in the design course. Third, the undergraduate mentors appear to receive a valuable experience, but the depth of that experience needs to be assessed formally.

As far as challenges, the question remains about how much writing improvement each student experiences since every major assignment, except for the job-application letter, is team- 
based. A second concern is given that the mentors should put their own course work before mentoring and grading, the writing instructor could find herself or himself in a jam if the course scales too much and the graders are not able to help.

\section{Broader Impact: Two writing modules from the pilot course have already spread to other courses in the College}

For an educational initiative to have widespread value, the initiative must be able to be scaled and sustained. This section discusses two modules from the pilot course that we have already begun transferring to other courses in the College. The first is a distillation of the job application email, which we have successfully piloted as a two-week module in a first-year seminar. The second is a report writing module, which we have successfully piloted as a lecture with pre- and post-exercises. The piloting has occurred in two large junior-level design courses (more than 300 electrical engineering students) and in a capstone design course (more than 200 civil engineering students).

Module on Job-Application Email. The first module is a distillation of the job email segment of the engineering writing course. Although every engineering student will receive a comparable module in the technical writing course that she or he eventually takes, our module targets courses during the first or second year. For that reason, the students have this module before applying for internships and undergraduate research positions that occur during the second and third years.

At present, we have successfully piloted this module in two first-year seminars to more than 70 students. The module on the job application email consists of the following sequence:

1. providing feedback on one diagnostic paragraph assigned before the module to help students avoid egregious mechanical errors in professional writing,

2. teaching two 50-minute class periods on writing a job application email, and then

3. grading the email submissions of the students (which occur over the next two weeks).

The diagnostic paragraph seeks to determine whether a student makes egregious mistakes of grammar, punctuation, and usage that would undercut a student's standing in job-application correspondence or other professional documents. The grammatical mistakes have arisen from a misguided education effort in the United States, in which many writing teachers from middle school to universities ceased to teach grammar in favor of more fun writing exercises such as first-person narratives [13]. The theory of this effort was that through reading, students would "catch" the rules for what defines a sentence. The result of this education effort has been that many students today do not understand what a sentence is and is not. To identify whether a student falls into this category, this first exercise calls on the students to use the adverbs however and therefore, which many mistakenly attempt to use with a comma to connect two independent clauses. Our application of this diagnostic to more than 500 students has found that about onethird of our U.S. engineering students make this error.

Likewise, to identify whether students struggle with common usage errors that result from not having been taught grammar or from a lack of reading of professional documents, the exercise calls on the students to use the following words: although, but, and either affect or effect. Administered on the course platform Canvas, the exercise allots only 15 minutes to write a paragraph on a topic such as a major challenge that the student has faced since coming to 
college. The instructor and a team of mentors mark this exercise using a code that identifies what is correct and incorrect. Students then receive the coded feedback in the grading key. Appendix B shows this grading key. A future assessment of this effort will be how effective this intervention is at helping students avoid these types of errors.

Two class periods, taught by the instructor or undergraduate mentors, accompany this job email module. These class periods cover the analysis of audience, purpose, and occasion of writing a job application email, the structure of this type of email, and the language (being precise, being clear, making connections, and controlling tone). To prepare undergraduate mentors to run these class periods, we provide detailed teaching notes in the notes pages of the teaching slides, which contain many actual examples and discussion opportunities for analysis of those examples. Our preliminary assessment is that the mentors need more training on running the class discussion of the examples.

The culmination of the job email module calls on the students to write a job application email for a summer internship or research position that they wish to apply. This assignment is meaningful for the students, because the email is the basis for correspondence that the students continually write during their studies. After appropriate training, mentors grade this assignment.

Module on Report Writing. The second module concerns report writing and targets upper-level design and laboratory courses. Essentially, this segment discusses the common stylistic differences between general writing courses, such as freshman composition, and engineering writing. The differences on which we focus have arisen from observations of the writings by undergraduate engineers. In other words, when engineering undergraduates begin to write as engineers writing, we have identified common stylistic errors that the students make and misconceptions that they hold? Making the observations have been the writing instructor and engineering instructors in laboratory and design courses across the College. Many of the errors and misconceptions arise from students holding onto a stylistic choice that might suit a descriptive essay in freshman composition, but would inappropriate in an engineering report [7]. Other errors arise from aspects of writing such as incorporating illustrations and equations that general writing courses do not teach. Table 3 presents a selection of these.

Table 3. Selection of Stylistic and Format Differences Between Engineering Writing and General Writing

\begin{tabular}{|c|c|}
\hline Category & Difference \\
\hline \multirow[t]{2}{*}{ Structure } & Titles in engineering are precise and clear-not "short and sweet" \\
\hline & Engineers state results up front in a summary - they do not keep the takeaway a mystery \\
\hline \multirow[t]{2}{*}{ Language } & $\begin{array}{l}\text { Engineers are precise in their writing - they do not exaggerate with words such as optimal or } \\
\text { prove }\end{array}$ \\
\hline & $\begin{array}{l}\text { Unlike creative writers, engineers do not tolerate ambiguity in their writing-for that reason, } \\
\text { engineers generally place commas after introductory phrases and clauses }\end{array}$ \\
\hline Illustration & Engineering audiences have specific expectations for inclusion of illustrations and equations \\
\hline Form & $\begin{array}{l}\text { In documents, engineers often follow sophisticated formats (layouts and typography) that serve the } \\
\text { audience and purpose (the format is not "typed, double-spaced") }\end{array}$ \\
\hline
\end{tabular}


While all engineering students should learn the information from this module in their technical writing course, our module is positioned to occur when the students are beginning to write in their design or laboratory courses. In addition, our module covers the incorporation of technical illustrations and equations, which are two topics that even a number of our institution's technical writing sections do not appear to cover.

At present, we have successfully piloted this report writing module as a lecture with preand post-exercises in two large junior-level design courses (more than 300 students) and a capstone design course (more than 200 students). The module for report writing consists of the following three steps:

1) providing feedback on one diagnostic paragraph to help students avoid common mechanical errors in professional writing,

2) teaching a 75-minute class period on avoiding stylistic errors in reports by young engineers, and then

3) administering a computer-graded quiz on avoiding those errors. The diagnostic paragraph is the same as discussed earlier. At present, because of the complexity of the 75-minute lecture, only the writing instructor teaches this class period. Finally, the computer-graded quiz is simply a multiple-choice quiz on the information presented in the class period. The purpose of the quiz is to reinforce the principles taught in the lecture. Because the quiz focuses on common misconceptions in engineering writing, a clear demarcation arises between those students who attend the lecture and those who do not.

\section{Conclusion: The approach of scaling the teaching of technical writing by using undergraduate mentors is promising, but requires a formal assessment}

This paper has presented the piloting of a new approach to teach technical writing that is distinctly different from the traditional one in which a communication instructor teaches sections of 20 to 30 engineering students. First, this new approach allows for larger sections. At present, the instructor is teaching 75 students across two sections, but next fall plans to increase that number to 100 students over two sections. To handle the larger mentoring and grading loads, the instructor relies on undergraduate mentors. Second, except for a job email assignment, this new approach aligns its assignments with a technical course such as junior-level design. The purpose of the alignment is to provide the students not only with technical content for the documents, but also with an actual audience, purpose, and occasion. Although the pilot effort of this approach shows promise, challenges remain. One challenge is that the teamwork integral to the design course makes it difficult to know the improvement of each student. A second challenge is that much needs to be learned about the effect of this work on the mentors. Yet a third challenge is that much still needs to be learned about the management of the mentors.

Ideally, a future assessment of this strategy will involve determining how much improvement of writing occurs with engineering students in the pilot course as compared with engineering students in a traditional technical writing course. One possible way to determine this question would be examining the quality of the writing assignments from the engineering writing course versus the quality of writing assignments in the institution's technical writing course. Another aspect of the assessment concerns determining how much value the mentors derive from the experience of mentoring and how the experience serves the mentors in their professional careers or graduate studies. Yet a third assessment would consider how much time and effort an 
instructor spends managing the engineering writing course versus teaching the same number of students in a traditional technical writing course. Required for all of these assessments would be an outside evaluator. Such an assessment would be valuable because even if the new approach falls short of the traditional approach, the assessment would confirm the choice of the traditional approach by so many institutions.

\section{Appendix A: Grading Rubric for the Job Application Email}

This appendix shows the grading rubric for the first major assignment: the job application email. In using this rubric, graders delete the comments that do not apply, thereby leaving only the writing strengths (in blue) and weaknesses (in red) that do. Scores for each perspective of the writing (structure, language, and form) are highlighted.

\section{Writing Grade}

\begin{tabular}{|c|c|c|c|c|c|}
\hline 30 & 32.5 & 35 & 37.5 & 40 & Structure \\
\hline 30 & 32.5 & 35 & 37.5 & 40 & Language \\
\hline 12 & 14 & 16 & 18 & 20 & Form: Format, Grammar, Punctuation, Usage, \\
\hline
\end{tabular}

\section{Writing Strengths}

Blue represents effective writing

\section{Structure}

Clear and precise title

First paragraph clearly orients us to purpose

Middle fashions a strong argument

Assertions of each middle paragraph backed up with cogent evidence

Resume referred to within email

Concluding paragraph provides closure

\section{Language}

Nice balance of $I$ and you

Clarity: You follow the principle of "one idea, one sentence"

Clarity: Language is as simple as possible, yet no simpler

Connections: Good use of transition words

Connections: Variety of sentence openers: dependent clause, prepositional phrase, infinitive phrase

Professional tone throughout

Form (Format, Grammar, Punctuation, Usage)

Professional format-template followed

Overall clean grammar, punctuation, and usage

\section{Writing Opportunities for Improvement}

Red type indicates a problem; green type indicates a suggestion

\section{Structure}

Title not specific enough 
Title contains a noun string that should be broken up

First paragraph does not state purpose of email

Unsupported assertion

More depth needed

Resume not referred to in the main text

Conclusion abrupt

\section{Language}

Too much / and not enough you

Exaggeration:

Ambiguity: Missing comma after introductory phrase or clause

Ambiguous use of standalone "this"

Imprecise word choice

Needless complexity: pretentious words, needless symbols, slash

Informal writing: avoid contractions, get, or a lot

Tonal error:

Too many sentences begin with the subject: You need more sophisticated sentence openers to make better connections between your ideas.

Form (Format, Grammar, Punctuation, Usage)

Run-on sentence: You cannot join two sentences with simply a comma-you need a period, semicolon, or a conjunction (and, but, or)

Wrong word: affect $\leftrightarrow$ effect, anxious $\leftrightarrow$ eager, its $\leftrightarrow$ it's

Grammar error:

Punctuation error:

Usage error:

Format error:

\section{Appendix B: Key for the Comments on Diagnostic Paragraph}

On your quiz, you will receive comments in the form of combinations of the following letters:

A B C $\mathbf{D}$ a b $\quad$ C $\mathbf{d}$ e $\mathbf{f}$

Each letter refers to a specific comment, which is explained below. In providing these comments, we have tried to help you avoid mistakes that will undercut your credibility with employers. The explanations of the comments come from [7].

\section{A: Correct use of affect or effect}

\section{B: Correct use and punctuation of although}

\section{C: Correct use and punctuation of however and therefore}

\section{D: Correct use and punctuation of but}

\section{a: Misuse of affect or effect}

The word affect is almost always a verb with the meaning to influence. The word effect, on the other hand, is usually a noun and means a result ("greenhouse effect"). A cause for confusion is that effect can also be used as a verb meaning to bring about: "She effected the change of orders." Adding even more confusion to the situation is that in the field of psychology, affect is used as a noun with the meaning of an "emotional 
response." Should you have a problem differentiating between these two words, then you should use affect solely as a verb meaning to influence and use effect solely as a noun meaning a result.

\section{b: Incorrect use of although}

In engineering and science, the word although is an important word to make an argument. In essence, the word although introduces a dependent clause that presents one side of an argument, and the independent clause that follows then presents the other side:

Although all of the wolves survived the rugged winter, the bitter cold and lack of food weakened many in the pack.

Given this use, the word although is never followed by a comma:

All of the wolves survived the rugged winter. Although, the bitter cold and lack of food weakened many in the pack.

Here, the author has simply used the wrong word. The word that the author wanted was however:

All of the wolves survived the rugged winter. However, the bitter cold and lack of food weakened many in the pack.

Because the word although is such an important and often used word in engineering and science, making the mistake given above seriously undercuts one's credibility.

\section{c: Run-on sentence with however or therefore}

Sentences are the fundamental units of expression in scientific documents. Readers of professional writing expect authors to write in sentences. When a sentence runs on, readers often lose their place in the paragraph. They also lose confidence in the author. The most common type of run-on sentence occurs when the writer tries to use an adverb such as however, otherwise, or therefore to join two independent clauses:

All of the wolves survived the rugged winter, however, the bitter cold and lack of food weakened many in the pack.

This group of words is a run-on-in this case, two sentences were joined incorrectly by a comma and the adverb "however." Several ways exist to correct the error:

All of the wolves survived the rugged winter. However, the bitter cold and lack of food weakened many in the pack. (rewritten as two sentences-note the mandatory comma after however)

All of the wolves survived the rugged winter; however, the bitter cold and lack of food weakened many in the pack. (comma replaced with semicolon)

All of the wolves survived the rugged winter, but the bitter cold and lack of food weakened many in the pack. (adverb replaced with conjunction)

Although all of the wolves survived the rugged winter, the bitter cold and lack of food weakened many in the pack. (first independent clauses made dependent)

Of the four proper corrections, the last is the most sophisticated because from the first word (although), the audience knows that the sentence is headed in one direction, but will turn back.

\section{d. Incorrect use or punctuation of but.}

The word but is a conjunction that can join two independent clauses. In scientific writing, this word does not begin a sentence. Rather, this word joins clauses or phrases. In general, a comma precedes this word. In addition, a comma never follows it.

\section{e. Missing comma after an introductory phrase or clause.}

To prevent ambiguity in engineering writing, you should insert a comma after an introductory phrase or clause. When engineers ignore this recommendation, ambiguity often results:

When feeding a shark often mistakes undesirable food items for something it really desires. 
A comma is required after the word feeding:

When feeding, a shark often mistakes undesirable food items for something it really desires.

Although general writing textbooks often treat a comma after an introductory phrase or clause as optional, scientific writing calls for this comma to avoid ambiguities or misreads.

f. Informal language: contractions (I've), wording (a lot) or starting a sentence with and or but The language of engineering writing is more formal than other types of writing such as fiction. For that reason, using contractions or beginning a sentence with a conjunction is too informal for most engineering documents.

\section{References}

1. R. House, A. Watt, and J. Williams (2007, June), "Assessing The Impact of Pen Based Computing on Students' Peer Review Strategies Using the Peer Review Comment Inventory,” 2007 Annual Conference \& Exposition, Honolulu, Hawaii. https://peer.asee.org/2052.

2. C. Nicometo, K. Anderson, T. Nathans-Kelly, S. Courter, and T. McGlamery (2010, June), "More Than Just Engineers-How Engineers Define and Value Communication Skills on the Job," 2010 Annual Conference \& Exposition (Louisville, Kentucky. https://peer.asee.org/16018).

3. C. Moore, D. Randall, and H. Hart (2009, June), "The Big Picture: Using the Unforeseen to Teach Critical Thinking,” 2009 Annual Conference \& Exposition (Austin, Texas. https://peer.asee.org/5595).

4. M. Alley, C. Dancey, and L. Vick (2005, April), "The Interweaving of Technical Communication Throughout the Curriculum of a Large Mechanical Engineering Department," 2005 Southeast Regional ASEE Conference (Chattanooga, Tennessee).

5. B. L. Yoder (2017), "Engineering by the Numbers," American Society of Engineering Education. https://www.asee.org/papers-and-publications/publications/collegeprofiles/15EngineeringbytheNumbersPart1.pdf.

6. B. Boyington (2017, September), "See 20 Years of Tuition Growth at National Universities." U.S. News \& World Report, https://www.usnews.com/education/best-colleges/paying-forcollege/articles/2017-09-20/see-20-years-of-tuition-growth-at-national-universities.

7. M. Alley, The Craft of Scientific Writing, $4^{\text {th }}$ ed. (New York: Springer-Verlag, 2018).

8. C. Bereiter and M. Scardamalia, The Psychology of Written Composition (Mahwah, NJ: Lawrence Erlbaum Associates, 1987), p. 360.

9. M. Lacey, E. Dibiase, and M. Frederick, "Model Presentation of an Engineering Design Project," https://vimeo.com/259568814 (University Park, PA: Penn State, December 2017).

10. A. Kumar, N. Nace, J. Benton and F. Santilli, "Proposal to Print a 3D-Model of a Paper Dryer Roller to Represent Bearing Failure," (University Park, PA: Penn State, December 2017).

11. S. Wilbers (1980), The Iowa Writers Workshop: Origins, Emergence, \& Growth (University of Iowa Press).

12. Illumin: A Review of Engineering in Everyday Life, vol. 18, issue 2 (Los Angeles: University of Southern California, 18 March 2018).

13. P. Tyre (2012), “The Writing Revolution,” The Atlantic Monthly, pp. 99-100. 